\title{
A new angucycline and a new butenolide isolated from lichen-derived Streptomyces spp.
}

\author{
Keiichiro Motohashi ${ }^{1}$, Motoki Takagi ${ }^{1}$, Hideki Yamamura ${ }^{2}$, Masayuki Hayakawa ${ }^{2}$ and Kazuo Shin-ya ${ }^{3}$ \\ A new 1,1-dichlorocyclopropane-containing angucycline, JBIR-88 (1), and a new butenolide, JBIR-89 (2), respectively, were \\ isolated from the fermentation broths of two lichen-derived actinomycetes identified as a new species of Streptomyces (strains \\ RI104-LiC106 and RI104-LiB101) using phylogenetic methods. The structures of 1 and 2 were elucidated on the basis of 1D \\ and 2D NMR spectroscopy and MS analyses. Compound 1 showed cytotoxic activities against cancer cells and antimicrobial \\ activity against Micrococcus luteus.
}

The Journal of Antibiotics (2010) 63, 545-548; doi:10.1038/ja.2010.94; published online 28 July 2010

Keywords: angucycline; antimicrobial activity; butenolide; cytotoxicity; dichlorocyclopropane; lichen; Streptomyces

\section{INTRODUCTION}

Lichens are composite and symbiotic organisms. Biologically, they often have been interpreted as one organism (fungi and algae associated within a common thallus), but taxonomically, they are classified as a life form of ascomycetous fungi. In all, $\sim 46 \%$ of the ascomycota are lichen forming; however, $2-3 \%$ of the lichen fungi are basidiomycota. Lichen-forming fungi produce a wide variety of secondary metabolites. The majority of lichen secondary metabolites are aromatic polyketides, and a number of these have been shown to exhibit biological activity. ${ }^{1}$ However, few reports of the isolation of actinobacteria from lichens or their products are available, and only one study reports that Streptomyces obtained from the surface of a lichen native to British Columbia produces uncialamycin, a new enediyne antibiotic. ${ }^{2}$ Thus, our intention was to provide evidence that new species of Streptomyces isolated from lichens are capable of producing unique metabolites. For this purpose, we isolated new species of Streptomyces from lichens and then searched for secondary metabolites in the cultures of the isolated strains. The isolated strains RI104-LiC106 and RI104-LiB101 were identified as new species of the genus Streptomyces by performing a homology search of their $16 \mathrm{~S}$ rRNA gene sequences. In the course of screening for novel metabolites of RI104-LiC106 and RI104-LiB101, we succeeded in isolating a new 1,1-dichlorocyclopropane-containing angucycline, designated as JBIR-88 (1), from the culture broth of RI104-LiC106, and a new butenolide, designated as JBIR-89 (2), from RI104-LiB101 (Figure 1). This paper describes the fermentation, isolation, structure elucidation and biological activities of $\mathbf{1}$ and 2 .

\section{RESULTS AND DISCUSSION}

Structure elucidation of 1

Strain RI104-LiC106 was cultured at $27^{\circ} \mathrm{C}$ on a rotary shaker. The acetone extract of mycelial cake from a fermentation broth (2l) was extracted with EtOAc. After drying over $\mathrm{Na}_{2} \mathrm{SO}_{4}$, the EtOAc layer was evaporated to dryness, and the dried residue $(670 \mathrm{mg})$ was subjected to normal- and reversed-phase chromatography to yield $\mathbf{1}(1.19 \mathrm{mg})$ as an orange oil. The molecular formula of 1 was obtained as $\mathrm{C}_{19} \mathrm{H}_{9} \mathrm{O}_{6} \mathrm{Cl}_{3}$ from its HR-electrospray ionization-MS (HR-ESI-MS), which showed a molecular ion at $m / z 438.9557[\mathrm{M}+\mathrm{H}]^{+}$.

The structure of 1 was clarified by analyses of the 2D NMR spectra, which included heteronuclear single-quantum coherence, heteronuclear multiple-bond correlation and double quantum filtered (DQF)COSY spectra (Figure 2). Table 1 shows the ${ }^{1} \mathrm{H}$ and ${ }^{13} \mathrm{C}$ NMR data recorded in $\mathrm{CDCl}_{3}$ from the heteronuclear single-quantum coherence analysis. The $o$-coupling correlation $\left({ }^{3} \mathrm{~J}_{\mathrm{H}-\mathrm{H}}=8.1 \mathrm{~Hz}\right)$ between doublet aromatic protons $\mathrm{H}-10\left(\delta_{\mathrm{H}} 7.80\right)$ and $\mathrm{H}-11\left(\delta_{\mathrm{H}} 7.64\right)$ was observed by DQF-COSY. In the heteronuclear multiple-bond correlation spectrum, the aromatic protons $\mathrm{H}-10$ and $\mathrm{H}-11$ were strongly $m$-coupled to aromatic quaternary carbons as follows: $\mathrm{H}-10$ to $\mathrm{C}-8\left(\delta_{\mathrm{C}} 157.9\right)$ and C-11a $\left(\delta_{C} 133.3\right)$, and $\mathrm{H}-11$ to $\mathrm{C}-7 \mathrm{a}\left(\delta_{\mathrm{C}} 115.9\right)$ and C-9 $\left(\delta_{\mathrm{C}} 129.7\right)$. In addition, $\mathrm{H}-11$ was ${ }^{1} \mathrm{H}_{-}{ }^{13} \mathrm{C}$ long-range coupled to a quinone carbonyl carbon C-12 $\left(\delta_{\mathrm{C}} 181.5\right)$ at the peri position and weakly W-type coupled to another quinone carbonyl carbon C-7 ( $\left.\delta_{C} 192.5\right)$. ${ }^{1} \mathrm{H}_{-}{ }^{13} \mathrm{C}$ long-range couplings from the phenolic hydroxyl proton $8-\mathrm{OH}\left(\delta_{\mathrm{H}} 12.21\right)$ to $\mathrm{C}-8$ and $\mathrm{C}-7 \mathrm{a}$, together with the low-field ${ }^{13} \mathrm{C}$ chemical shift at C-7 $\left(\delta_{\mathrm{C}} 192.5\right)$ compared with $\mathrm{C}-12\left(\delta_{\mathrm{C}} 181.5\right)$,

${ }^{1}$ Biomedicinal Information Research Center (BIRC), Japan Biological Informatics Consortium (JBIC), Tokyo, Japan; ${ }^{2}$ Interdisciplinary Graduate School of Medicine and Engineering, University of Yamanashi, Kofu, Japan and ${ }^{3}$ Biomedicinal Information Research Center (BIRC), National Institute of Advanced Industrial Science and Technology (AIST), Tokyo, Japan

Correspondence: Dr K Shin-ya, Biomedicinal Information Research Center (BIRC), National Institute of Advanced Industrial Science and Technology (AIST), 2-4-7 Aomi, Koto-ku, Tokyo 135-0064, Japan.

E-mail: k-shinya@aist.go.jp

or Dr M Takagi, Biomedicinal Information Research Center (BIRC), Japan Biological Informatics Consortium (JBIC), 2-4-7 Aomi, Koto-ku, Tokyo 135-0064, Japan. E-mail: motoki-takagi@aist.go.jp

Received 9 June 2010; revised 30 June 2010; accepted 1 July 2010; published online 28 July 2010 
<smiles>O=C1c2c(ccc(Cl)c2O)C(=O)c2c1c(O)cc1c2[C@@H](O)[C@@H]2C(=O)C1(Cl)[C@@H]2Cl</smiles>

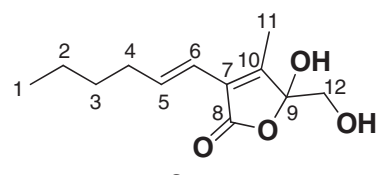

2<smiles>CCC1CC(=O)c2c(cc(O)c3c2C(=O)c2c(O)cccc2C3=O)C1</smiles>

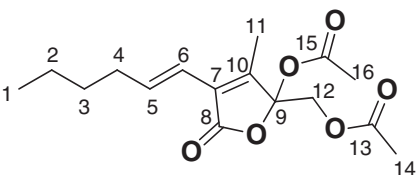

3

Figure 1 Structures of 1-3 and brasiliquinone.

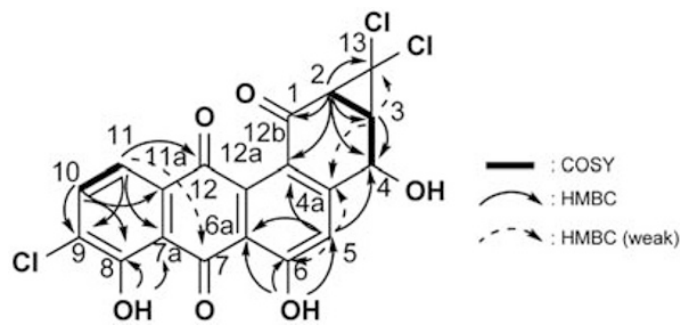

Figure 2 Key correlations between double quantum filtered-COSY (bold lines) and heteronuclear multiple-bond correlation (arrows) spectra of 1.

supported the existence of the hydrogen-bonded phenolic hydroxyl proton with the quinine carbonyl carbon $\mathrm{C}-12$. Taken together, these data indicated the presence of a naphthoquinone moiety in $\mathbf{1}$ (Figure 2).

The sequence from a doublet methine proton $\mathrm{H}-2\left(\delta_{\mathrm{H}} 3.13\right)$ to an oxymethine proton $\mathrm{H}-4\left(\delta_{\mathrm{H}} 5.24\right)$ through a double doublet methine proton $\mathrm{H}-3$ was observed in the DQF-COSY spectrum. The six-membered ring structure shown in Figure 2 was established by ${ }^{1} \mathrm{H}-{ }^{13} \mathrm{C}$ long-range couplings from the methine proton $\mathrm{H}-2$ to an $\alpha, \beta$-unsaturated carbonyl carbon $\mathrm{C}-1\left(\delta_{\mathrm{C}} 189.1\right)$ and an aromatic quaternary carbon $\mathrm{C}-12 \mathrm{~b}\left(\delta_{\mathrm{C}} 126.6\right)$, which in turn strongly $m$-coupled to an aromatic proton $\mathrm{H}-5\left(\delta_{\mathrm{H}} 7.51\right)$, and from $\mathrm{H}-5$ to an oxymethine carbon $\mathrm{C}-4\left(\delta_{\mathrm{C}} 64.7\right)$ and an aromatic quaternary carbon $\mathrm{C}-4 \mathrm{a}\left(\delta_{\mathrm{C}} 152.1\right)$, which in turn was long-range coupled to the methine proton $\mathrm{H}-3$. Both $\mathrm{H}-2$ and $\mathrm{H}-3$ were ${ }^{1} \mathrm{H}-{ }^{13} \mathrm{C}$ long-range coupled to a quaternary carbon $\mathrm{C}-13\left(\delta_{\mathrm{C}} 60.4\right)$. Thus, C-2, C-3 and $\mathrm{C}-13$ were considered to form a cyclopropane moiety. ${ }^{1} \mathrm{H}-{ }^{13} \mathrm{C}$ longrange couplings from a phenolic hydroxyl proton $6-\mathrm{OH}\left(\delta_{\mathrm{H}} 12.18\right)$ to C-5 $\left(\delta_{\mathrm{C}} 120.3\right)$, C-6 $\left(\delta_{\mathrm{C}} 164.9\right)$ and C-6a $\left(\delta_{\mathrm{C}} 117.4\right)$, which in turn strongly $m$-coupled to an aromatic proton $\mathrm{H}-5$, established the assignment of these carbons. Although no correlation to a quaternary aromatic carbon $\mathrm{C}-12 \mathrm{a}\left(\delta_{\mathrm{C}} 136.5\right)$ was detected, this carbon was assigned to the remaining naphthoquinone moiety. These assignments are also supported by comparing ${ }^{13} \mathrm{C}$ NMR chemical shifts with those of brasiliquinone B. ${ }^{8}$ The molecular formula of 1 suggests that three hydroxyl groups and three chlorine atoms are substituted at C-4, C-6 and C-8, and at C-9 and C-13, respectively. Therefore, these spectral data prove the formation of a 1,1-dichlorocyclopropane ring comprising C-2, C-3 and C-13. To confirm the 1,1-dichlorocyclopropane ring

Table $1{ }^{13} \mathrm{C}(150 \mathrm{MHz})$ and ${ }^{1} \mathrm{H}$ NMR $(600 \mathrm{MHz})$ spectroscopic data for 1 in $\mathrm{CDCl} 3$

\begin{tabular}{|c|c|c|}
\hline \multirow[b]{2}{*}{ Position } & \multicolumn{2}{|c|}{1} \\
\hline & ${ }^{13} \mathrm{C}$ & ${ }^{1} H(J$ in $H z)$ \\
\hline 1 & 189.1 & \\
\hline 2 & 42.4 & $3.13 \mathrm{~d}(10.7)$ \\
\hline 3 & 38.3 & $3.03 \mathrm{dd}(10.7,5.9)$ \\
\hline 4 & 64.7 & $5.24 \mathrm{~d}(5.9)$ \\
\hline $4 a$ & 152.1 & \\
\hline 5 & 120.3 & $7.51 \mathrm{~s}$ \\
\hline 6 & 164.9 & \\
\hline $6 a$ & 117.4 & \\
\hline 7 & 192.5 & \\
\hline $7 a$ & 115.9 & \\
\hline 8 & 157.9 & \\
\hline 9 & 129.7 & \\
\hline 10 & 138.0 & $7.80 \mathrm{~d}(8.1)$ \\
\hline 11 & 120.6 & $7.64 \mathrm{~d}(8.1)$ \\
\hline $11 a$ & 133.3 & \\
\hline 12 & 181.5 & \\
\hline $12 a$ & 136.5 & \\
\hline $12 b$ & 126.6 & \\
\hline 13 & 60.4 & \\
\hline $6-\mathrm{OH}$ & & $12.18 \mathrm{~s}$ \\
\hline $8-\mathrm{OH}$ & & $12.21 \mathrm{~s}$ \\
\hline
\end{tabular}

Abbreviation: H NMR, proton nuclear magneticresonance.

in $\mathbf{1}$, the ${ }^{1} J_{\mathrm{C}-\mathrm{H}}$ and ${ }^{13} \mathrm{C}$ NMR chemical shifts of $\mathbf{1}$ were compared with those of 1,1-dichloro-7,7a-dihydro- $1 \mathrm{H}$-cyclopropa[b]naphthalene$2(1 \mathrm{a} H)$-one. ${ }^{9}$ Results showed that the ${ }^{1} J_{\mathrm{C}-\mathrm{H}}$ large values of $\mathrm{C}-2$ $(178.5 \mathrm{~Hz})$ and $\mathrm{C}-3(175.3 \mathrm{~Hz})$ in 1 were almost identical to those of C-2 $(172 \mathrm{~Hz})$ and C-3 $(169 \mathrm{~Hz})$ in 1,1-dichloro-7,7a-dihydro$1 H$-cyclopropa[ $b]$ naphthalene-2 $(1 \mathrm{a} H)$-one. In addition, the ${ }^{13} \mathrm{C} \mathrm{NMR}$ chemical shifts of the 1,1-dichloropropane ring in $\mathbf{1}$ were similar to those of $\mathrm{C}-2\left(\delta_{\mathrm{C}} 37.8\right), \mathrm{C}-3\left(\delta_{\mathrm{C}} 30.7\right)$ and $\mathrm{C}-13\left(\delta_{\mathrm{C}} 60.7\right)$ in 1,1-dichloro-7,7a-dihydro- $1 H$-cyclopropa $[b]$ naphthalene-2( $1 \mathrm{a} H)$-one, with the exception of the disappearance of the hydroxyl group at C-4. Thus, the structure of $\mathbf{1}$ was determined as shown in Figure 1.

Structure elucidation of 2

Similar to strain RI104-LiC106, strain RI104-LiB101 was cultured and extraction of the mycelial acetone extract was performed using EtOAc. The dried residue of the EtOAc layer $(670 \mathrm{mg})$ then was subjected to normal- and reversed-phase chromatography to yield $2(1.22 \mathrm{mg})$ as a colorless oil. The molecular formula of 2 was determined to be $\mathrm{C}_{20} \mathrm{H}_{23} \mathrm{ClN}_{4} \mathrm{O}_{7}$ on the basis of HR-ESI-MS data $(\mathrm{m} / z 467.1305$ $\left.[\mathrm{M}+\mathrm{H}]^{+}\right)$. The ${ }^{1} \mathrm{H}$ and ${ }^{13} \mathrm{C}$ NMR spectral data for 2 are shown in Table 2. The structural information for $\mathbf{2}$ was obtained by the series of 2D NMR analyses (Figure 3a). The sequence from a triplet methyl proton $\mathrm{H}-1\left(\delta_{\mathrm{H}} 0.90\right)$ to a doublet olefinic proton $\mathrm{H}-6\left(\delta_{\mathrm{H}} 6.03\right)$ through the methylene protons $\mathrm{H}-2\left(\delta_{\mathrm{H}} 1.34\right), \mathrm{H}-3\left(\delta_{\mathrm{H}} 1.42\right), \mathrm{H}-4$ $\left(\delta_{\mathrm{H}} 2.18\right)$ and an olefinic methine proton $\mathrm{H}-5\left(\delta_{\mathrm{H}} 6.84\right)$ was established by the analyses of the DQF-COSY spectrum. The structural relationships among C-7, C-8, C-9 and C-10 were established by ${ }^{1} \mathrm{H}-{ }^{13} \mathrm{C}$ long-range couplings from a singlet methyl proton $\mathrm{H}-11$ $\left(\delta_{\mathrm{H}} 2.03\right)$ to the olefinic quaternary carbons $\mathrm{C}-7\left(\delta_{\mathrm{C}} 126.6\right), \mathrm{C}-10$ $\left(\delta_{\mathrm{C}}\right.$ 153.0) and the acetal quaternary carbon C-9 $\left(\delta_{\mathrm{C}} 104.8\right)$, and from H-6 to an ester carbonyl carbon C-8 $\left(\delta_{C} 170.2\right)$ and the 
Table $2{ }^{13} \mathrm{C}(150 \mathrm{MHz})$ and ${ }^{1} \mathrm{H}$ NMR $(600 \mathrm{MHz})$ spectroscopic data for 2 in $\mathrm{CDCl}_{3}$ and ${ }^{13} \mathrm{C}(125 \mathrm{MHz})$ and ${ }^{1} \mathrm{H}$ NMR $(500 \mathrm{MHz})$ spectroscopic data for 3 in $\mathrm{CDCl}_{3}$

\begin{tabular}{|c|c|c|c|c|}
\hline \multirow[b]{2}{*}{ Position } & \multicolumn{2}{|r|}{2} & \multicolumn{2}{|r|}{3} \\
\hline & ${ }^{13} \mathrm{C}$ & ${ }^{1} H(J$ in $H z)$ & ${ }^{13} \mathrm{C}$ & ${ }^{1} H(J$ in $H z)$ \\
\hline 1 & 14.2 & $0.90 \mathrm{t}(7.4)$ & 14.2 & $0.91 \mathrm{t}(7.3)$ \\
\hline 2 & 22.5 & $1.34 \mathrm{~m}$ & 22.6 & $1.35 \mathrm{~m}$ \\
\hline 3 & 31.2 & $1.42 \mathrm{~m}$ & 31.1 & $1.43 \mathrm{~m}$ \\
\hline 4 & 33.8 & $2.18 \mathrm{q}(7.1)$ & 33.9 & 2.19 q (7.0) \\
\hline 5 & 140.3 & $6.84 \mathrm{dt}(15.8,7.1)$ & 140.5 & $6.87 \mathrm{dt}(15.8,7.0)$ \\
\hline 6 & 117.2 & $6.03 \mathrm{~d}(15.8)$ & 117.0 & $6.05 \mathrm{~d}(15.8)$ \\
\hline 7 & 126.6 & & 127.2 & \\
\hline 8 & 170.2 & & 168.7 & \\
\hline 9 & 104.8 & & 103.5 & \\
\hline 10 & 153.0 & & 150.4 & \\
\hline 11 & 11.2 & $2.03 \mathrm{~s}$ & 10.9 & $1.99 \mathrm{~s}$ \\
\hline 12 & 65.4 & $3.75 \mathrm{~m}$ & 62.8 & $4.47 \mathrm{~d}(11.6), 4.37 \mathrm{~d}(11.6)$ \\
\hline 13 & & & 170.2 & \\
\hline 14 & & & 20.8 & $2.03 \mathrm{~s}$ \\
\hline 15 & & & 167.8 & \\
\hline 16 & & & 21.7 & $2.08 \mathrm{~s}$ \\
\hline
\end{tabular}

Abbreviation: H NMR, proton nuclear magneticresonance.

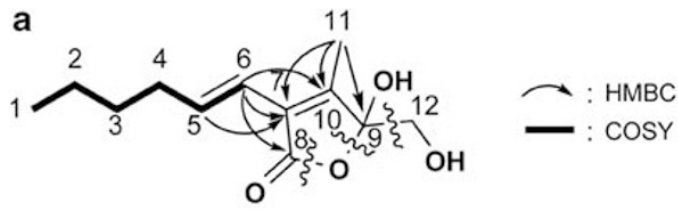

b

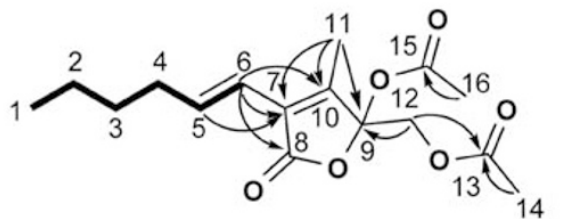

Figure 3 Key correlations between double quantum filtered-COSY (bold lines) and heteronuclear multiple-bond correlation (arrows) spectra of 2 (a) and 3 (b).

olefinic quaternary carbons $\mathrm{C}-7$ and $\mathrm{C}-10$. The remaining unit, a hydroxymethyl carbon C-12 $\left(\delta_{\mathrm{H}} 3.75, \delta_{\mathrm{C}} 65.4\right)$, was not assigned because of the lack of heteronuclear multiple-bond correlation due to signal broadening.

To establish the structure of $\mathbf{2}$, the acetylation of $\mathbf{2}$ was performed to simplify the proton-coupling pattern of the hydroxymethyl C-12 and to determine the cyclized site. The correlation between ${ }^{1} \mathrm{H}$ and ${ }^{13} \mathrm{C}$ signals for the diacetate derivative of JBIR-89 (3) was established by heteronuclear single-quantum coherence analysis (Table 2). In the heteronuclear multiple-bond correlation spectrum of $3,{ }^{1} \mathrm{H}-{ }^{13} \mathrm{C}$ longrange correlations of the methylene proton $\mathrm{H}-12\left(\delta_{\mathrm{H}} 4.47\right.$ and 4.37$)$, the acetal carbon $\mathrm{C}-9\left(\delta_{\mathrm{C}} 103.5\right)$ and the carbonyl carbon C-13 $\left(\delta_{\mathrm{C}}\right.$ 170.2), which in turn long-range coupled to a singlet methyl proton $\mathrm{H}-14\left(\delta_{\mathrm{H}} 2.03\right)$, were observed. Other DQF-COSY and ${ }^{1} \mathrm{H}_{-}{ }^{13} \mathrm{C}$ long-range correlations are identical to those of 2 (Figure $3 \mathrm{~b}$ ). Therefore, the structure of 2 was determined to be 3-(hex-1-en-1-yl)-5hydroxy-5-(hydroxymethyl)-4-methylfuran-2(5H)-one (Figure 1).

\section{Biological activity}

To observe the biological activity of $\mathbf{1}$ and 2, cytotoxic and antimicrobial activities were examined. Compound 1 exhibited cytotoxic activity against HeLa and ACC-MESO-1 cells with $\mathrm{IC}_{50}$ values of 36 and $52 \mu \mathrm{M}$, respectively. However, 2 was inactive against both cells $\left(\mathrm{IC}_{50}\right.$ values $\left.>250 \mu \mathrm{M}\right)$. In addition, 1 exhibited antibacterial activity (inhibition zone, $11 \mathrm{~mm}$ at a concentration of $25 \mu \mathrm{g}$ on $6 \mathrm{~mm}$ disk) against Micrococcus luteus, but showed no antimicrobial activity against Candida albicans and Escherichia coli. Detailed investigation into the biological activity of $\mathbf{1}$ is currently underway.

In conclusion, we isolated JBIR-88 (1), possessing a unique substructure 1,1-dichlorocyclopropane ring moiety, from the strain RI104-LiC106, and isolated JBIR-89 (2) from RI104-LiB101 as a butenolide ${ }^{10}$ derivative. The structure of 1 was found to be structurally related to BE-23254 isolated from Streptomyces sp. A 23254. ${ }^{11}$ However, this is the first report of a tetraphene containing the dichlorocyclopropane ring. The results of this study suggest that new species of Streptomyces isolated from lichens have the ability to produce new compounds and may serve to encourage chemists to investigate the isolation of actinobacteria from lichens.

\section{MATERIALS AND METHODS}

General experimental procedures

Optical rotations were obtained on an SEPA-300 polarimeter (Horiba, Kyoto, Japan). UV and IR spectra were measured on a DU730 UV/Vis spectrophotometer (Beckman Coulter, CA, USA) and an FT-720 spectrophotometer (Horiba), respectively. NMR spectra were recorded on a Varian NMR System 500 or $600 \mathrm{NB}$ CL (Varian, Palo Alto, CA, USA) in $\mathrm{CDCl}_{3}$ (7.24 p.p.m. for ${ }^{1} \mathrm{H}$, 77.0 p.p.m. for ${ }^{13} \mathrm{C}$ ) with the residual solvent peak as the internal standard. HR-electrospray ionization-MS (HR-ESI-MS) data were recorded on an LCT-Premier XE mass spectrometer (Waters, Milford, MA, USA). Normalphase medium-pressure liquid chromatography was performed using a Purifpack SI-60 column (Moritex, Tokyo, Japan). Analytical reversed-phase HPLC was carried out using an MGII ODS column (4.6 i.d. $\times 150 \mathrm{~mm}$; Shiseido, Tokyo, Japan) equipped with a 2996 photodiode array detector (Waters) and a 3100 Mass Detector (Waters). Preparative reversed-phase HPLC was carried out using an MGII ODS column (20 i.d. $\times 150 \mathrm{~mm}$; Shiseido).

\section{Microorganisms}

The producing Streptomyces designated as RI104-LiC106 and RI104-LiB101 was isolated from the whole body of a lichen collected from Risiri Island, Hokkaido Prefecture, Japan by the moist incubation and desiccation method. ${ }^{3}$ The basic local alignment search tool search of the 16S rRNA gene sequence of RI104-LiC106 (GenBank: AB552917) and RI104-LiB101 (GenBank: AB552918) showed that the strains belonged to new species of the genus Streptomyces.

\section{Fermentation}

Streptomyces sp. RI104-LiC106 and RI104-LiB101 were cultivated in 50-ml test tubes each containing $15 \mathrm{ml}$ of a seed medium consisting of starch $1 \%$ (Kosokagaku, Tokyo, Japan), polypeptone 1\% (Nihon Pharmaceutical, Tokyo, Japan), molasses 1\% (Dai-Nippon Meiji Sugar, Tokyo, Japan) and meat extract 1\% (Extract Ehlrich, Wako Pure Chemical Industries, Osaka, Japan), pH 7.2 (before sterilization). The test tubes were shaken on a reciprocal shaker (355 r.p.m.) at $27^{\circ} \mathrm{C}$ for 2 days. Aliquots $(2.5 \mathrm{ml})$ of the broths were transferred to 500-ml baffled Erlenmeyer flasks containing $100 \mathrm{ml}$ of a production medium corresponding to each strain and cultured on a rotary shaker (180 r.p.m.) at $27^{\circ} \mathrm{C}$ for 5 days. The production medium for RI104-LiC106 consisted of $\beta$-cyclodextrin 4\% (Kanto Chemical, Tokyo, Japan), glycerin $0.5 \%$, pharmamedia $2 \%$ (Traders Protein, Memphis, TN, USA), $\mathrm{CuSO}_{4} 5 \mathrm{mg}, \mathrm{MnCl}_{2} 5 \mathrm{mg}$ and $\mathrm{ZnSO}_{4} 5 \mathrm{mg}$, pH 7.2 (before sterilization). The production medium for RI104-LiB101 consisted of glycerin $2 \%$, molasses $1 \%$, casein $5 \%$ (Kanto Chemical) and $\mathrm{CaCO}_{3}$ (Kozakai Pharmaceutical, Tokyo, Japan) $0.4 \%$, pH 7.2 (before sterilization). 


\section{Isolation of 1}

The mycelial cake obtained from the fermentation broth (2l) was extracted with $\mathrm{Me}_{2} \mathrm{CO}(500 \mathrm{ml})$. The extract was concentrated in vacuo, and the aqueous concentrate was extracted with EtOAc $(100 \mathrm{ml} \times 3)$. After drying over $\mathrm{Na}_{2} \mathrm{SO}_{4}$, the organic layer was evaporated to dryness. The residue $(670 \mathrm{mg})$ was subjected to normal-phase medium-pressure liquid chromatography (Purif-Pack SI-60, Moritex) and successively eluted with a gradient system of $n$-hexane-EtOAc $\left(0-30 \%\right.$ EtOAc) and $\mathrm{CHCl}_{3}-\mathrm{MeOH}(0-50 \% \mathrm{MeOH})$. The $1 \%$ $\mathrm{MeOH}$-eluted fraction $(52.9 \mathrm{mg})$ was purified by preparative reversed-phase HPLC using an MGII ODS column (20 i.d. $\times 150 \mathrm{~mm}$, Shiseido) with $70 \%$ $\mathrm{MeOH}-\mathrm{H}_{2} \mathrm{O}$ containing $0.1 \%$ formic acid (flow rate $8.0 \mathrm{ml} \mathrm{min}^{-1}$ ) to yield $\mathbf{1}$ $(1.19 \mathrm{mg}$, retention time $=13.3 \mathrm{~min})$.

\section{Isolation of 2}

The fermentation broth (2l) was centrifuged, and the mycelial cake was extracted with $\mathrm{Me}_{2} \mathrm{CO}(500 \mathrm{ml})$. After concentration in vacuo, the aqueous concentrate was extracted with EtOAc $(100 \mathrm{ml} \times 3)$. After being dried over $\mathrm{Na}_{2} \mathrm{SO}_{4}$, the organic layer was evaporated to dryness. The residue $(410 \mathrm{mg})$ was subjected to normal-phase medium-pressure liquid chromatography (Purif-Pack SI-60, Moritex) and successively eluted with a gradient system of $n$-hexane-EtOAc $\left(0-30 \%\right.$ EtOAc) and $\mathrm{CHCl}_{3}-\mathrm{MeOH}(0-50 \% \mathrm{MeOH})$. The $1 \%$ $\mathrm{MeOH}$-eluted fraction $(35.8 \mathrm{mg})$ was purified by preparative reversed-phase HPLC using an MGII ODS column (20 i.d. $\times 150 \mathrm{~mm}$, Shiseido) with $60 \%$ $\mathrm{MeOH}-\mathrm{H}_{2} \mathrm{O}$ containing $0.1 \%$ formic acid (flow rate $8.0 \mathrm{ml} \mathrm{min}^{-1}$ ) to yield 2 $(1.22 \mathrm{mg}$, retention time $=11.7 \mathrm{~min})$.

JBIR-88 (1): orange oil; $[\alpha]_{\mathrm{D}}-190(c 0.1, \mathrm{MeOH}) ; \mathrm{UV}(\mathrm{MeOH}) \lambda_{\max }(\log \varepsilon)$ 438 (4.16) and $271(4.66) \mathrm{nm}$; IR (KBr) $v_{\max } 3030,1690,1670$ and $1630 \mathrm{~cm}^{-1}$; ${ }^{1} \mathrm{H}$ NMR $\left(600 \mathrm{MHz}, \mathrm{CDCl}_{3}\right)$ and ${ }^{13} \mathrm{C}$ NMR $\left(150 \mathrm{MHz}, \mathrm{CDCl}_{3}\right)$, see Table 1; HR-ESI-MS $m / z 438.9557[\mathrm{M}+\mathrm{H}]^{+}\left(\right.$calcd for $\left.\mathrm{C}_{19} \mathrm{H}_{10} \mathrm{O}_{6} \mathrm{Cl}_{3}, 438.9543\right)$.

JBIR-89 (2): colorless oil; $[\alpha]_{\mathrm{D}}+15(c 0.1, \mathrm{MeOH}) ; \mathrm{UV}(\mathrm{MeOH}) \lambda_{\max }(\log \varepsilon)$ $261(3.60) \mathrm{nm}$; IR (KBr) $v_{\max } 3040$ and $1760 \mathrm{~cm}^{-1} ;{ }^{1} \mathrm{H}$ NMR $(600 \mathrm{MHz}$, $\left.\mathrm{CHCl}_{3}\right)$ and ${ }^{13} \mathrm{C} \mathrm{NMR}\left(150 \mathrm{MHz}, \mathrm{CHCl}_{3}\right)$, see Table 2; HR-ESI-MS $\mathrm{m} / \mathrm{z}$ 227.1286 $[\mathrm{M}+\mathrm{H}]^{+}$(calcd for $\mathrm{C}_{12} \mathrm{H}_{19} \mathrm{O}_{4}, 227.1283$ ).

\section{Acetylation of 2}

A sample of $2(1.0 \mathrm{mg})$ was dissolved in $100 \mu \mathrm{l}$ of pyridine, mixed with $10 \mu \mathrm{l}$ of acetic anhydride and stirred at room temperature for $2 \mathrm{~h}$. The mixture was diluted with $\mathrm{MeOH}$, evaporated in vacuo and applied to preparative reversedphase HPLC using an MGII ODS column (20 i.d. $\times 150 \mathrm{~mm}$, Shiseido) developed with $75 \% \mathrm{MeOH}-\mathrm{H}_{2} \mathrm{O}$ (flow rate $8.0 \mathrm{ml} \mathrm{min}^{-1}$ ) to yield JBIR-89 diacetate $(3 ; 0.62 \mathrm{mg}$, retention time $=10.6 \mathrm{~min})$.

\section{Biological activity}

Cytotoxicity against human cervical carcinoma HeLa cells and human malignant pleural mesothelioma ACC-MESO-1 cells ${ }^{4-7}$ were determined by a colorimetric assay, using 2-(2-methoxy-4-nitrophenyl)-3-(4-nitrophenyl)-5(2,4-disulfophenyl)-2H-tetrazolium monosodium salt. Cells were cultured in Dulbecco's modied Eagle's medium (Wako Pure Chemical Industries) for HeLa cells or RPMI medium (Nacalai Tesque, Kyoto, Japan) for ACC-MESO-1 cells, supplemented with $10 \%(\mathrm{v} / \mathrm{v})$ fetal bovine serum (Invitrogen, Carlsbad, CA, USA), penicillin $\left(100 \mathrm{units}^{-1}\right)$ and streptomycin $\left(100 \mu \mathrm{g} \mathrm{ml}^{-1}\right)$ at $37^{\circ} \mathrm{C}$ in a humidified incubator under a $5 \% \mathrm{CO}_{2}$ atmosphere. The 384-well plates were seeded with aliquots of a $20-\mu \mathrm{l}$ medium containing $1 \times 10^{3}$ cells per well and were incubated overnight before being treated with compounds at various concentrations for $48 \mathrm{~h}$. Plates were incubated for $1 \mathrm{~h}$ at $37^{\circ} \mathrm{C}$ after the addition of $2 \mu \mathrm{l}$ of 2-(2-methoxy-4-nitrophenyl)-3-(4-nitrophenyl)-5-(2,4-disulfophenyl)$2 \mathrm{H}$-tetrazolium monosodium salt reagent solution (Cell Counting Kit; Dojindo, Kumamoto, Japan) per well. The absorption of the formed formazan dye was measured at $450 \mathrm{~nm}$. The vehicle solvent (dimethyl sulfoxide) was used as a negative control. Paclitaxel as a positive control showed cytotoxicity against HeLa and ACC-MESO- 1 cells with $\mathrm{IC}_{50}$ values of 30 and $24 \mathrm{~nm}$, respectively.

Antimicrobial activity against $M$. luteus ATCC 9341 was measured by a paper disk method. A paper disk (i.d. $6 \mathrm{~mm}$ ) containing $25 \mu \mathrm{g}$ of a sample was placed on an LB agar plate consisting of yeast extract 5\% (BD Biosciences, San Jose, CA, USA), peptone $1 \%$ (BD Biosciences) and $\mathrm{NaCl} 1 \%$, and the plate was incubated at $27^{\circ} \mathrm{C}$ for $24 \mathrm{~h}$. Antimicrobial activity was expressed as diameter $(\mathrm{mm})$ of the inhibitory zone.

\section{ACKNOWLEDGEMENTS}

This work was supported by a grant from the New Energy and Industrial Technology Development Organization (NEDO), Japan.

1 Stocker-Worgotter, E. Metabolic diversity of lichen-forming ascomycetous fungi: culturing, polyketide and shikimate metabolite production, and PKS genes. Nat. Prod. Rep. 25, 188-200 (2008).

2 Davies, J. et al. Uncialamycin, a new enediyne antibiotic. Org. Lett. 7, 5233-5236 (2005).

3 Matsukawa, E., Nakagawa, Y., limura, Y. \& Hayakawa, M. A new enrichment method for the selective isolation of Streptomycetes from the root surfaces of herbaceous plants. Actinomycetologica 21, 66-69 (2007).

4 Izumikawa, M., Khan, S. T., Komaki, H., Takagi, M. \& Shin-Ya, K. JBIR-31, a new teleocidin analog, produced by salt-requiring Streptomyces sp. NBRC 105896 isolated from a marine sponge. J. Antibiot. 63, 33-36 (2010).

5 Motohashi, K., Hwang, J. H., Sekido, Y., Takagi, M. \& Shin-ya, K. JBIR-23 and -24, novel anticancer agents from Streptomyces sp. AK-AB27. Org. Lett. 11, 285-288 (2009).

6 Ueda, J. Y., Takagi, M. \& Shin-ya, K. Aminocaprophenone- and pyrrolidine-type alkaloids from the leaves of Ficus septica. J. Nat. Prod. 72, 2181-2183 (2009).

7 Usami, N. et al. Establishment and characterization of four malignant pleural mesothelioma cell lines from Japanese patients. Cancer Sci. 97, 387-394 (2006).

8 Tsuda, M. et al. Brasiliquinones A-C, new cytotoxic benz[a]anthraquinones with an ethyl group at C-3 from actinomycete Nocardia brasiliensis. J. Chem. Soc., Perkin. Trans. 1, 1173-1775 (1996).

9 Kelly, D. P., Banwell, M. G., Ireland, N. K. \& Noel, A. L. ${ }^{13} \mathrm{C}^{-1} \mathrm{H}$ coupling constants in carbocations. 6. Generation and trapping of the (1a. $\alpha, 7 a . \alpha)-1 a, 2,7,7 a-t e t r a h y d r o-$ 1 H-cyclopropa[b]naphthalen-2-yl cation. J. Org. Chem. 56, 2040-2045 (1991).

10 Braun, D., Pauli, N., Sequin, U. \& Zahner, H. New butenolides from the photoconductivity screening of Streptomyces antibioticus (Waksman and Woodruff) Waksman and Henrici 1948. FEMS Microbiol. Lett. 126, 37-42 (1995).

11 Okabe, T., Ogino, H., Suzuki, H., Okuyama, A. \& Suda, H. Jpn. Kokai Tokkyo Koho. JP92, 316-492 (1992). 